\title{
The costs of hospitalization in patients with acute exacerbation of chronic obstructive pulmonary disease
}

This article was published in the following Dove Press journal:

ClinicoEconomics and Outcomes Research

14 January 2011

Number of times this article has been viewed

\author{
Sevket Ozkaya' \\ Serhat Findik ${ }^{2}$ \\ Atilla Guven Atici ${ }^{2}$ \\ 'Rize University, Department \\ of Pulmonary Medicine, Rize, \\ Turkey; ${ }^{2}$ Ondokuz Mayis University, \\ Department of Pulmonary Medicine, \\ Atakum, Samsun, Turkey
}

\begin{abstract}
Introduction: Chronic obstructive pulmonary disease (COPD) is a major public health problem. It imparts a substantial economic burden on individuals and society. Acute exacerbations are the main cause of hospital admissions and hospitalizations in patients with COPD in Turkey.

Objectives: We aimed to determine the costs of hospitalization in patients with acute exacerbations of COPD (AECOPD).

Results: A total of 7832 (1556 women, $6276 \mathrm{men}$ ) patients were hospitalized due to acute exacerbations of COPD between 2005-2009 in the Samsun Chest Diseases and Thoracic Surgery Hospital, northern Turkey. The mean age was $64.6 \pm 19.8$ years old and median length of hospital stay was $14.8 \pm 9.5$ days. The mean cost per admission was US\$718 \pm 364 . Drug costs accounted for the largest portion (53.5\%) of the mean cost, followed by bed cost (19.6\%). One hundred seventy-four (2.2\%) of the total hospitalized patients with AECOPD died in hospital. Conclusion: AECOPD continues to have both significant economic burden and high mortality rate.
\end{abstract}

Keywords: COPD, acute exacerbation, hospitalization, costs

\section{Introduction}

Although chronic obstructive pulmonary disease (COPD) is a preventable and treatable disease, it remains a significant public health problem. COPD is a major chronic cause of mortality and morbidity and it has been identified as the fourth leading cause of mortality and morbidity. Unlike many leading causes of death and disability, COPD is projected to increase in much of the world as smoking habits rise and the population ages. $^{1,2}$ It was estimated by the World Health Organization (WHO) in 2000 that 274 million people worldwide died of COPD. ${ }^{3}$ Acute exacerbation is the main cause of hospitalization in patients with COPD. The number of patients hospitalized for acute exacerbation of COPD (AECOPD) accounts for $13 \%$ of all admitted patients. ${ }^{4}$ It imparts a substantial economic burden on individuals and society. Hospitalization for acute exacerbations represents a major component of the socioeconomic burden related to COPD. ${ }^{5}$ Hilleman et al reported that hospitalization costs represent $40.4 \%$ of total health care costs for patients with mild COPD, and $62.6 \%$ of total costs for patients with severe COPD. ${ }^{6}$ Very few studies have quantified the economic and premature mortality associated with COPD. The aim of this study was to determinate the costs of hospitalization in patients with AECOPD.

\section{Material and methods}

Samsun is the biggest city in the Black Sea region of Turkey. Samsun Chest Diseases and Thoracic Surgery Hospital is the reference hospital for chest diseases and thoracic 
surgery in northern Turkey. More than 100,000 patients with respiratory problems are referred to the hospital per year. Diagnosis of AECOPD (emphysema and/or chronic bronchitis) was based on the presence of any combination of the following symptoms: increased dyspnea and increased production and purulence of sputum that led to a change or increase in treatment. This study aimed to investigate the costs in hospitalized patients with AECOPD. Data on AECOPD management were retrospectively taken and evaluated directly from the medical records. Costs in this analysis were identified for drugs (including short-acting and long-acting $\beta$-agonists, ipratrobium, theophylline, inhaled and oral steroids, and antibiotics), oxygen therapy, non invasive mechanical ventilation, emergency department visit, laboratory tests, diagnostic tests, and hospitalizations. The Institutional Review Board approved the use of medical records. As a state hospital, all expenditure was at prices set by the state. Expenditure was calculated in US dollars (exchange rate at the time of the study, 1.5 Turkish liras per US dollar).

\section{Results}

The results of the study and characteristics of patients are presented in Table 1. A total of 60,529 patients with COPD were seen in the Samsun Chest Diseases and Thoracic Surgery Hospital. 7832 (12.9\%) patients were hospitalized due to mild and moderate AECOPD; $19.8 \%$ of patients were women $(n=1556)$ and $80.1 \%$ of patients were men

Table I Characteristics of patients

\begin{tabular}{ll}
\hline Characteristics & $\mathbf{n}(\%)$ \\
\hline Total number of COPD patients & 60529 \\
Hospitalized COPD patients & $7832(12.9)$ \\
Premature mortality & $174(2.2)$ \\
Age (mean \pm SD years) & $64.6 \pm 19.8$ \\
Male & $6276(80.1)$ \\
Female & $1556(19.8)$ \\
Costs by year (US\$) & \\
2005 & $\$ 668$ \\
2006 & $\$ 765$ \\
2007 & $\$ 768$ \\
2008 & $\$ 667$ \\
2009 & $\$ 682$ \\
Mean cost (US\$) & $\$ 718 \pm 364$ \\
Distribution of costs & \\
Drug & $53.5 \%$ \\
Bed & $19.6 \%$ \\
Laboratory & $9.8 \%$ \\
Radiology & $6.2 \%$ \\
Examination & $4.6 \%$ \\
Emergency department & $3.9 \%$ \\
Other & $2.4 \%$ \\
\hline
\end{tabular}

Abbreviation: COPD, chronic obstructive pulmonary disease. $(n=6276)$. The mean age of patients was $64.6 \pm 19.8$ years. The median length of hospital stay was $14.8 \pm 9.5$ days. The numbers of patients hospitalized per year were 1061 , 1952, 1794, 1144, and 1181 in 2005, 2006, 2007, 2008, and 2009 , respectively. The mean hospital costs per admission were $\$ 668$ in 2005, \$765 in 2006, \$768 in 2007, \$667 in 2008 , and $\$ 682$ in 2009 . The mean cost of hospitalization over 5 years was $\$ 718 \pm 364 /$ per admision. The percentages of mean costs are demonstrated in Figure 1. Drug costs were the highest $(53.5 \%)$ followed by bed cost $(19.6 \%)$, laboratory $(9.8 \%)$, radiology $(6.2 \%)$, examination $(4.6 \%)$ and emergency department costs $(3.9 \%)$, and other (noninvasive ie, ventilation) costs (2.4\%). Of the total hospitalized patients with AECOPD, 174 (2.2\%) patients died in hospital. Progressive respiratory failure, lung cancer, pulmonary infections, and cardiovascular comorbidities were major causes of death in hospitalized patients with AECOPD.

\section{Discussion}

COPD is a major public health problem. It is a costly disease with both direct costs (value of health care resources devoted to diagnosis and medical management) and indirect costs (monetary consequences of disability, missed work, premature mortality, and caregiver or family costs resulting from the illness). According to reported articles, hospital admission rates are suitable for detecting the health burden of COPD., ${ }^{4,7}$ Acute exacerbations are the main cause of hospitalization in patients with COPD. Hospitalization-related costs are the largest portion of all expenditure for patients with COPD. Hospitalization costs

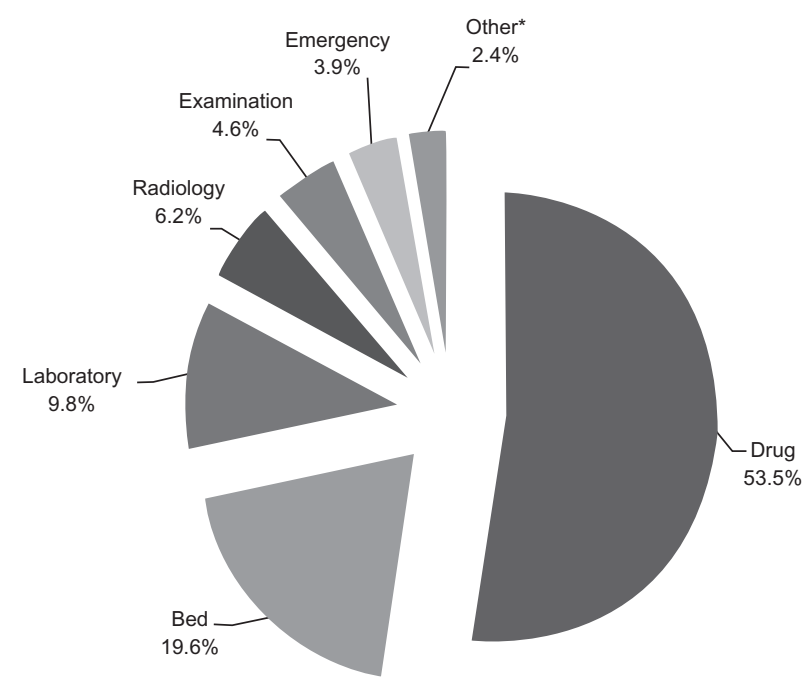

Figure I Distribution of mean costs (2005-2009) acute exacerbation of chronic obstructive pulmonary disease.

Note: *non-invazive mechanical ventilation, bronchoscopy, echocardiography, ... 
represent between $40 \%$ and $57 \%$ of total direct costs generated by patients with COPD. ${ }^{5,9-12}$ The exacerbations account for $35 \%-45 \%$ of the total per capita health care costs for COPD. ${ }^{4}$ Hilleman et al reported that the hospitalization costs of patients with mild, moderate, and severe COPD were $\$ 680, \$ 2,658$, and $\$ 6770$, respectively. ${ }^{6}$ Recent studies showed that there are variable differences in mean costs of AECOPD between countries. The cost of hospitalization for COPD was calculated to be $\$ 7,100$ in United States and $\$ 2,652$ in Spain. The mean costs of our study were lower than those of other studies. ${ }^{9}$ Miravitlles et al noted the mean cost of AECOPD was \$239.7 for hospitalization for 15 days. ${ }^{4}$ In our study, the mean cost of hospitalization due to AECOPD per admission was $\$ 718 \pm 364$ between 2005 and 2009. The median length of hospital stay was $14.8 \pm 9.5$ days. The reported studies presented different percentages of costs. According to one article in Spain, reported the highest cost was hospitalization (58\%) and drug acquisition was $32.2 \% .^{10}$ In China, the highest absolute cost was drug cost (71.2\%), followed by laboratory cost (16.7\%), and bed cost was the lowest cost (4.1\%). ${ }^{14}$ In the present study, the percentage of drug cost was the highest $(53.5 \%)$, followed by bed cost $(19.6 \%)$. We know that the different costs are related to the differences in reference prices (drugs, laboratory), management practices, and health care systems. ${ }^{4}$ In Turkey, the bed cost is lower, but drug prices are higher than in other European countries. Furthermore, the mean cost of this study was lower than reported studies because patients who needed the intensive care unit (ICU) were not included in this study.

Nurmagambetov et al reported the estimated COPDrelated total medical costs per patient decreased $22 \%$ largely with a decrease in the cost of hospitalizations for COPD. ${ }^{15}$ Although many investigatons have found inpatient mortality rates associated with COPD exacerbations to be between $2.5 \%$ and $4 \%$, GOLD has reported an overall rate of $10 \%$, which increases to $40 \%$ in 1 year. ${ }^{18,19}$ Groenewegen et al reported the mortality rate during hospital stay was $8 \% .{ }^{8}$ We detected a premature mortality rate during hospitalization of $2.2 \%$ in patients with AECOPD. Our result was lower than in other studies because the patients who needed intensive care were not included this study. (the patients who needed intensive care were referred to the university hospital). In the present study, progressive respiratory failure, lung cancer, pulmonary infections, and cardiovascular comorbidities appear to be major causes of death in hospitalized patients. Other studies reported in-hospital mortality rates $11 \%-24 \%$. $^{7,16,17}$
In these studies, the high mortality rates were caused by mechanical ventilation and ICU.

In conclusion, acute exacerbations of COPD continues to have both significant economic burden and high mortality rate.

\section{Disclosure}

The authors report no conflicts of interest in this work.

\section{References}

1. Hurd S. The impact of COPD on lung health worlwide: epidemiology and incidence. Chest. 2000;117:1S-4S.

2. Murray CJ, Lopez AD. Alternative projections of mortality and disability by cause 1990-2020: Global Burden of Disease Study. Lancet. 1997;349:1498-1504.

3. Global Initiative for Chronic Obstructive Pulmonary Disease. Global strategy for the diagnosis, treatment and prevention of chronic obstructive pulmonary disease; 2006. Available from: http://www. goldcopd.com. Accessed 2010 Dec 10.

4. Miravitlles M, Murio C, Guerrero T, Gisbert R. Pharmacoeconomic evaluation of acute exacerbations of chronic bronchitis and COPD. Chest. 2002;121:1449-1455.

5. Rutten van Molken MP, Postma MJ, Joore MA, et al. Current and future medical costs of asthma and COPD in The Netherlands. Respir Med. 1999;93:779-787.

6. Hilleman DE, Dewan N, Malesker M, et al. Pharmacoeconomic evaluation of COPD. Chest. 2000;118:1276-1285.

7. Seemungal TAR, Hurst JR, Wedzicha JA. Exacerbation rate, health status and mortality in COPD - a review of potential interventions. Int J COPD. 2009;4:203-223.

8. Groenewegen KH, Schols AMWJ, Wouters EFM. Mortality and mortality-related factors after hospitalization for acute exacerbation of COPD. Chest. 2003;124(2):459-467.

9. Sullivan SD, Ramsey SD, Lee TA. The economic burden of COPD Chest. 2000;117(Suppl 5S):5S-9S.

10. Connors AF Jr, Dawson NV, Thomas C, et al. Outcomes following acute exacerbation of severe COPD: the SUPPORT Investigators (Study to Understand Prognosis and Preferences for Outcomes and Risks of Treatments). Am J Respir Crit Care Med. 1996;154:959-967.

11. Jacobson L, Hertzman P, Löfdahl CG, et al. The economic impact of asthma and chronic obstructive pulmonary disease (COPD) in Sweeden in 1980 and 1991. Respir Med. 2000;94:247-255.

12. Wilson L, Devine EB, So K. Direct medical costs of chronic obstructive pulmonary disease: chronic bronchitis and emphysema. Respir Med. 2000;94:204-213.

13. Andersson F, Borg S, Jansson S-A, Jonsson A-C, et al. The costs of exacerbations in chronic obstructive pulmonary disease (COPD). Respir Med. 2002;96:700-708.

14. Chen Y, Yao WZ, Cai BQ, et al. Economic analysis in admitted patients with acute exacerbation of chronic obstructive pulmonary disease. Chin Med J. 2008;121:587-591.

15. Nurmagambetov T, Atherly A, Williams S, Holguin F, Mannino DM, Redd SC. What is the costs to employers of direct medical car efor chronic obstructive pulmonary disease? COPD. 2006;3:20-39.

16. Hurd $\mathrm{S}$. The impact of COPD on lung health worldwide: epidemiology and incidence. Chest. 2000;117:1S-4S.

17. Seneff MG, Wagner DP, Wagner RP, et al. Hospital and 1-year survival of patients admitted to intensive care units with acute exacerbation of chronic obstructive pulmonary disease. JAMA. 1995; 274:1852-1857.

18. Fuso L, Incalzi RA, Pistelli R, et al. Predicting mortality of patients hospitalized for acutely exacerbated chronic obstructive pulmonary disease. Am J Med. 1995;98:272-277. 
19. Mushlin AI, Black ER, Connoly CA, Buonaccorso KM, Eberly SW. The necessary length of hospital stay for chronic pulmonary disease. JAMA. 1991;266:80-83.
20. Skrepnek GH, Skrepnek MD. Epidemiology, clinical and economic burden, and natural history of chronic pulmonary disease and asthma. Am J Manag Care. 2004;10:129-138.

\section{Publish your work in this journal}

ClinicoEconomics \& Outcomes Research is an international, peerreviewed open-access journal focusing on Health Technology Assessment, Pharmacoeconomics and Outcomes Research in the areas of diagnosis, medical devices, and clinical, surgical and pharmacological intervention. The economic impact of health policy and health systems organization also constitute important areas of coverage. The manuscript management system is completely online and includes a very quick and fair peer-review system, which is all easy to use. Visit http://www.dovepress.com/testimonials.php to read real quotes from published authors.

Submit your manuscript here: http://www.dovepress.com/clinicoeconomics-and-outcomes-research-journal 